Sichman, J. S.; Bousquet, F.; Davidsson, P. (Eds.) Multi-agent-based simulation II. Lecture Notes in Artificial Intelligence. Berlin, Germany, Springer-Verlag. Vol. 2581, p. 105-124. 2003.

19. Schelling, T.. Micromotives and macrobehavior. W. W. Norton \& Company. 1978.

20. Rapaport, W. J. "Implementation is semantic interpretation". The Monist, 82(1), p. 109-130.1999.

21. David, N.; Sichman, J. S.; Coelho, H.. "The logic of the method of agent-based simulation in the social sciences: empirical and intentional adequacy of computer programs". Journal of Artificial Societies and Social Simulation, 8(4). 2005.

22. David, N.; Sichman, J. S.; Coelho, H.. "Simulation as formal and generative social science: the very idea". In: Gershenson, C.; Aerts, D.; Edmonds, B. (Eds.) Worldviews, science, and us: philosophy and complexity. World Scientific Publishing. p. 266-284. 2007.

23. Küppers, G.; Lenhard, J. (2005). "Validation of simulation: patterns in the social and natural sciences". Journal of Artificial Societies and Social Simulation, 8(4), 2005.

\section{A BIOLOgIA DE SÍNTESE E O PROBLEMA DA EMERGENCIA DA VIDA}

\author{
Entrevista com Mark Bedau
}

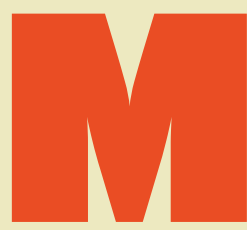

ark Bedau é considerado um dos especialistas mais reconhecidos na área da biologia de síntese e vida artificial. Professor no Reed College (Portland, EUA), ele foi criado em um ambiente filosófico - seu pai era um filósofo-, e ele obteve seu doutorado em filosofia na Universidade de Berkeley, Estados Unidos. Ele é editor-chefe do periódico Artificial Life e publicou vários livros sobre o assunto. Nesta entrevista, realizada por Remy Lestienne por email, Bedau trata sobre o campo da emergência da vida e as questóes que envolvem a criação de vida artificial e sobre os desafios da biologia de síntese. "Nossos poderes de criar novas formas de vida estão em progresso e em desenvolvimento, de modo que é cada vez mais urgente exercer essas capacidades de uma maneira prudente e responsável", pondera Bedau.

Como você foi atraído para o campo da emergência da vida, considerado ainda como novidade na área de pesquisa científica e filosófica?

O filósofo que há em mim está interessado nas mais fundamentais questôes sobre os mais básicos aspectos da realidade. Penso que a maior parte das pessoas concorda em dizer que a vida é um aspecto básico da realidade. As coisas que são vivas e ativas diferem daquelas que são inertes e passivas. Sabemos muito a propósito da biologia molecular das formas simples de vida, e sabemos modelizar sistemas vivos, e este conhecimento fornece restrições empíricas úteis referentes à especulação filosófica. Igualmente importante são as simulaçôes computacionais do tipo bottom-up. Logo no início da minha carreira vi como as simulaçôes informáticas com computadores podem revelar estruturas emergentes nas redes complexas regidas por leis causais, de modo que incluí simulaçôes com computadores nas ferramentas filosóficas que costumava usar. O valor epistêmico das simulaçôes em computadores é capturado pela noção de emergência fraca - que é a característica costumeira e evidente das qualidades emergentes aparecendo nas simulaçōes informáticas complexas de tipo bottom-up. Mais tarde, completei minhas ferramentas com uma grande quantidade de dados empíricos obtidos nas experimentaçōes nos laboratórios úmidos, embora minha contribuição pessoal seja somente o programa (software) para modelizar os dados experimentais e predizer quais provas experimentais novas podem revelar melhor as respostas emergentes. Estas experiências com computadores, que podemos caracterizar como feitas por um "robô cientista", permitem engenhar sistemas bioquímicos complexos que mostram as propriedades emergentes desejadas. Um alvo era planejar ou "programar" o que chamamos de protocélulas, isto é, sistemas químicos mínimos, os mais simples possível, embora bastante complexos para 
mostrar todas as características chave dos sistemas vivos. Sendo muito simples, estes sistemas químicos mínimos podem revelar muito sobre as características essenciais dos sistemas vivos, o que interessa aos filósofos. Naturalmente, o projeto de fabricar novas formas de vida em laboratório levanta um grande número de assuntos éticos e sociais importantíssimos. Portanto, fui também envolvido em iniciativas intelectuais e sociais que promovem práticas relevantes da chamada responsabilidade social científica.

Seu trabalho trata de um ponto muito importante que abre a possibilidade para a verdadeira emergência no mundo, no sentido filosófico moderno da palavra, ou seja, para a manifestação de novas e irreduzíveis propriedades de sistemas quando eles atravessam certos patamares de complexidade. De fato, a vida parece ter atravessado vários patamares desse tipo. De forma breve, gostaria de mencionar as sucessivas aparições das bactérias (procariotas) e vírus, dos eucariotas (células com um núcleo separado), e dos seres vivos pluricelulares. Você acredita que o conceito de emergência deve se aplicar a cada um desses passos, no sentido fraco (epistemológico) ou forte (ontológico) do conceito?

Deixe-me primeiro definir alguns tipos chave de emergência. Eu chamo de emergência criativa o que se refere ao crescimento contínuo da complexidade máxima manifestado pelos organismos vivos em sua evolução histórica. Isso é o tipo de emergência à qual sua pergunta está se referindo. Deixe-me dizer que o conceito de emergência forte refere-se a uma propriedade de uma totalidade que exerce algumas potências causais "brutas", isto é, potências causais que são irreduzíveis, a princípio, a qualquer combinação das potências causais das partes do sistema (e de suas organizaçōes). Em contraste, refiro-me à emergência fraca quando se trata de propriedades produzidas quando redes complexas de causas regem sistemas construídos de um modo bottom-up.

A característica distintiva dos sistemas assim construídos (bottom-up totalidades) é que a matéria da qual eles são compostos consta exclusivamente do conjunto de matérias constituindo as partes, o estado da totalidade consta exclusivamente da combinação dos estados das suas partes, e as causas que regem o estado da totalidade são, exclusivamente, a combinação de causas que regem as suas partes. Se a rede de interações causais entre as partes de uma totalidade do tipo bottom-up é simples, então predizer o estado exato do sistema global a qualquer momento no futuro é um problema simples, conhecendo exatamente as condições iniciais de todas as suas partes (e conhecendo as condições limites e qualquer contingência aplicável para sistemas abertos). Mas se a rede de interações causais entre as partes do sistema bottom-up é suficientemente complexa, então a única maneira de predizer os estados exatos futuros do sistema é calcular, passo a passo, o efeito da rede de causas no futuro e computar cada um dos sucessivos estados de cada parte. Uma rede complexa de causas desse tipo é o que define a emergência fraca.
A emergência fraca é frequentemente descrita como uma emergência "epistemológica". Essa descrição é, em parte, correta, mas também, em parte, falsa. É errado pensar que as totalidades que mostram propriedades emergentes do tipo fracas não têm propriedades ontológicas distintivas. A emergência fraca resulta de uma rede complexa de causas que regem certos sistemas globais bottom-up. Essa rede complexa de causas é uma propriedade real do mundo real. Não é possível prever o comportamento exato futuro de uma simples bactéria, se não através de uma tediosa computação considerando a rede de causas, pois este comportamento é regido precisamente por uma rede complexa de causas. Por outro lado, é correto pensar que a emergência fraca tem consequências epistemológicas características e importantes. Por causa da complexidade das redes de causas, tomemos conhecimento das propriedades de emergência do tipo fraca dos sistemas segundo certos caminhos emblemáticos. Redes complexas de causas explicam a importância das simulações computacionais de tipo bottom-up; este tipo de computação constitui a ferramenta perfeita para observar o efeito de seguir o procedimento das redes de causas. De modo que a emergência fraca explica o papel central das simulações computacionais de tipo bottom-up nas ciências da complexidade.

Uma segunda consequência epistêmica das redes complexas de causas é a importância da síntese, resumida no famoso aforismo de Richard Feynman: "O que não podemos criar, não compreendemos". Tendo em vista que não podemos derivar as propriedades emergentes fracas a partir dos primeiros princípios, uma maneira construtiva de considerar as propriedades emergentes produzidas por um certo tipo de rede complexa de causas é simplesmente criar essa rede e observar o seu comportamento. Uma vez criado o sistema com as propriedades emergentes desejadas, pode-se observar como essas propriedades mudam quando se modifica as partes. Às vezes, pode-se descobrir novas estruturas na resposta emergente do sistema e se mapear as várias regiōes da resposta do sistema. Essas estruturas e mapas são regras empíricas que permitem uma melhor exploração das propriedades emergentes. Criar sistemas com as propriedades emergentes desejadas constitui uma excelente maneira de apreender a ciência dessas propriedades.

As reflexões acima nos leva à terceira e a mais fundamental consequência da emergência fraca: o fato de que essa ciência depende de muitos dados empíricos. Porque as propriedades emergentes não podem ser preditas, o verdadeiro método para apreender sobre propriedades emergentes é a observação dos acontecimentos do sistema nas várias condiçōes, como foi tentado de fato. O que finalmente equivale a ensaios exaustivos e observaçóes dos êxitos e erros, o que nos faz pensar em ensaios famosos realizados sem descanso por Thomas Edison na procura de um filamento ideal para as primeiras lâmpadas eléctricas. Quando observaçóes empíricas e exaustivas se revelam uma das melhores maneiras de apreender novas coisas sobre o comportamento de um sistema, podemos suspeitar de estar na presença de uma rede complexa de causas que levam a propriedades emergentes fracas. 
Agora, com estas definições na mão, deixe-me finalmente responder a suas questôes. A emergência criativa de formas de vida mais complexas, a partir de formas mais simples ao longo da história da vida sobre a Terra, é um fato inegável. Contudo, até hoje ninguém conhece os mecanismos precisos graças aos quais isso aconteceu. De fato, ninguém sabe até como isso pode ter acontecido, em princípio, por que ninguém sabe como construir um modelo computacional bottom-up que mostre o crescimento correto da complexidade máxima. De modo que, por enquanto, a emergência criadora permanece um mistério. Pessoalmente, penso na evolução biológica como um processo essencialmente bottom-up, e as redes de causas implicadas como certamente complexas o bastante para gerar uma multidão de estruturas emergentes fracas. E uma dessas estruturas é a emergência criativa. Se estou certo sobre isso, então a emergência criativa não envolve emergência de tipo forte. A emergência fraca é suficiente. Dizer isso é também confessar minha ignorância, pois não sei exatamente qual tipo de emergência fraca está envolvida na emergência criativa. Um teste para saber se você compreende a emergência criativa é mostrar se você é capaz de construir um modelo bottom-up manifestando as características da emergência criativa. Por enquanto, não posso fazer isso, e hoje ninguém pode. Criar um modelo computacional bottom-up manifestando propriedades da emergência criadora é como o Santo Graal para todos os proponentes da emergência fraca.

Pode-se pensar que os ingredientes necessários para o aparecimento de propriedades emergentes, de modo geral, são tempo (e a vida claramente necessitou muito tempo para aparecer na Terra!) e abertura. Só sistemas abertos, isto é, que permitem intercâmbios de energia, entropia, e/ou matéria parecem elegíveis para que propriedades emergentes possam aparecer. Essas condições são de fato necessárias para que a vida possa atravessar os patamares dos quais falamos anteriormente?

O exemplo principal de emergência na filosofia da mente é o surgimento da consciência. A todo momento, uma pessoa tem certos estados conscientes da mente. No mesmo instante, o cérebro dessa pessoa e o seu sistema nervoso central (e também o resto do seu corpo e seu ambiente local) estão em vários estados físicos (e químicos e biológicos). A hipótese de uma intervenção de emergência aqui é que o estado consciente da mente dessa pessoa, a um dado momento, emerge do estado físico neste mesmo momento. Este tipo de emergência é sincrônico; ela ocorre em um instante de tempo. Isso demostra que o tempo não é essencial para o tipo de emergência estática implicada nos estados conscientes da mente.

Ao contrário, a emergência fraca que descrevi acima é, por essência, diacrônica. A emergência fraca diz respeito à complexidade da rede de causas, e essa complexidade é manifestada pela maneira pela qual o comportamento do sistema se desenrola dinamicamente ao longo do tempo. A emergência fraca aparece quando as interaçóes causais entre as partes são tão complexas que o comportamento da totalidade não pode estar comprimido ao longo do tempo. Assim, o tempo é central para a definição mesma da emergência fraca.
O que podemos dizer sobre a abertura? A emergência existe apenas em sistemas abertos? Se você enfoca sua atenção sobre algum organismo vivo, tal como uma bactéria, é claro que se está considerando um sistema aberto. A bactéria colhe matéria e energia do meio ambiente, e descarta resíduos; o metabolismo faz com que o organismo seja um sistema aberto, trocando matéria e energia com o meio ambiente. Da mesma maneira, a rede complexa de causas que rege as totalidades bottom-up manifestando propriedades emergentes fracas, tipicamente implica em interações com entidades do meio ambiente. Por essa razão, totalidades bottom-up com propriedades emergentes fracas são geralmente sistemas abertos.

Mas se se amplia bastante a visão, então a questão da abertura torna-se controversa. A ciência contemporânea diz que o universo real é finito; ele ocupa somente uma quantidade finita de espaço, e ele existiu somente por uma quantidade finita de tempo. Assim, o universo inteiro tal como ele existe é um sistema fechado. Em consequência disso, todo exemplo concreto de emergência fraca tem que existir nesse sistema fechado, e a abertura não pode estar em uma condição necessária da emergência. Uma ilustração bastante simples desse ponto é dado pelos autômatos celulares tal como o chamado Game of Life. Estes autômatos celulares são sistemas fechados, mas mostram muitos comportamentos característicos da emergência fraca (e talvez também de outros tipos de emergência). Assim, a abertura certamente não é necessária para a emergência fraca (e pelas mesmas razões, a estocasticidade também não é necessária, como vamos discutir abaixo).

Certos sábios adicionariam o acaso como um ingrediente necessário para que propriedades emergentes apareçam. Por exemplo, diz-se que a transcrição do DNA em RNA e a sua tradução em proteínas não são completamente regidas por regras determinísticas, mas obedecem também a alguma estocasticidade (1).

Deixe-me presumir que a ciência contemporânea ensina que algumas leis que regem o comportamento de objetos físicos fundamentais no mundo real sejam estocásticas. Portanto, qualquer objeto físico no mundo real que manifeste propriedades emergentes seria regido por um certo nível de leis estocásticas. Mas os aspetos interessantes do comportamento emergente talvez não sejam afetados por essas leis, pois diferences estocásticas poderiam produzir o mesmo comportamento emergente. Assim, mesmo no caso em que objetos físicos fundamentais obedeçam a leis estocásticas, o comportamento emergente dos sistemas globais não seria afetado. Finalmente, a estocasticidade não é necessária para a emergência em geral e para a vida em particular, mesmo que ela esteja normalmente presente nos dois. A meu ver, o que faz a diferença é a complexidade da rede de causas que produz o comportamento do sistema global. Mesmo se as leis fundamentais que regem as partes não sejam estocásticas, mas determinísticas, as redes de causas bottom-up podem ter o tipo de complexidade que produz a emergência fraca, como os autômatos celulares do tipo do Game of Life mostram. São as redes complexas de causas que produzem as propriedades emergentes, inclusive as propriedades emergentes dos sistemas vivos. 
Tratemos agora dos problemas fascinantes da vida artificial e da biologia de síntese. Será que podemos sonhar em produzir a vida em laboratórios, a partir de matéria puramente inerte? Em anos recentes, houve alguns progressos espantosos nesta direção, tais como a síntese do genoma de vários vírus, ou a famosa experiência desenvolvida por Craig Venter e sua equipe nos Estados Unidos - a completa síntese do genoma da bactéria Mycoplasma mycoides (com mais de um milhão de nucleotídeos) e o êxito de seu transplante em uma outra bactéria, Mycoplasma capricolum. Essa experiência levou à eliminação do genoma original dessa última bactéria e a sua substituição pela forma sintética e, finalmente, para o funcionamento normal da bactéria assim modificada, inclusive seu metabolismo e replicação. $\mathrm{O}$ que o senhor acha desses progressos?

Em 2010, o Instituto J. Craig Venter (JVCI) anunciou que criara uma célula sintética. De fato, a célula do JVCI era apenas parcialmente sintética. Ela foi fabricada através da substituição do genoma natural de uma bactéria natural pelo genoma artificial sintetizado a partir de matéria ordinária e inerte; todo o resto na célula JVCI em questão era parte de uma bactéria viva normal. Exceto por algumas mudanças triviais, tais como marcas genéticas específicas e genes para produzir uma tinta azul, o genoma sintético da célula JVCI era um cópia exata do genoma de uma bactéria natural. Assim, a célula JVCI marca apenas um pequeno passo.

Porém, a célula JVCI abre portas para muitos outros passos, e passos ainda maiores. $\mathrm{O}$ mesmo método usado poderia produzir um genoma de uma bactéria fabricada para manifestar qualquer combinação desejada de características conhecidas. A composição do genoma poderia ser muito diferente dos genomas naturais, e consistir em qualquer sequência específica de nucleotídeos. Ademais, métodos usados na pesquisa de protocélulas (o que chamo de biologia de síntese bottom-up) nos permite sintetizar todos os outros componentes contidos no interior da membrana celular. Essas células completamente sintéticas estariam livres das contingências e erros acidentais manifestados pelas formas vivas existentes, e provavelmente eles seriam muito mais simples do que a mais simples célula viva natural. Ademais, os benefícios práticos de células sintéticas exigem uma grande reprogramação celular; muito trabalho e engenhosidade são requeridos para fazer com que bactérias produzam produtos preciosos tais como combustíveis ou fármacos. Eventualmente as células sintéticas úteis poderão então se tornar bastante artificiais.

As células sintéticas são sintéticas de três maneiras. Primeiro, elas existem somente por causa das ações conscientes e intencionais de um grupo de cientistas humanos; elas são sintéticas porque são artefatos. Segundo, elas são constituídas de matéria inerte, o tipo de matéria que se pode encomendar de um fornecedor qualquer de produtos químicos. O grau com o qual uma célula está vindo de fontes inertes pode variar; na célula JVCI, só o material genômico é sintético. Terceiro, uma célula de síntese pode ser uma forma muito nova de vida, uma forma que difere muito de todas as formas naturais de vida. Existem muitos modos de fazer com que uma célula de síntese difira das formas naturais de vida; uma delas é de juntar ou tirar muitos genes vindos de uma grande diversidade de espécies. Ser uma nova forma de vida é uma questão de gradação; algumas formas novas de vida diferem pouco das formas naturais enquanto outras podem diferir muito. A célula JVCI era somente um exemplo criado artificialmente de forma natural de vida, mas há muito ainda por vir. Podemos esperar ver, em um futuro não tão distante, células totalmente sintéticas, produzidas exclusivamente a partir de materiais inertes.

O método da biologia de síntese usando pedaços padronizados é uma estratégia direta para tratar das propriedades emergentes dos sistemas vivos. A engenharia tradicional desenha e produz sistemas complexos de uma maneira modular e de tipo top-down, cujo objetivo é fabricar sistemas que não têm propriedades emergentes inesperadas e se comportam exatamente como desejado. O sistema global é dividido nas suas partes, e suas partes são ainda divididas em subpartes, e esse processo é repetido até chegar aos componentes primários que são pedaços simples e padronizados, disponíveis nos fornecedores industriais. Essas componentes padronizadas de tipo plug-and-play podem facilmente estar inseridas ou removidas nos desenhos modulares, de modo que é fácil para engenheiros humanos conceber (ou idear) máquinas desprovidas de comportamentos não previstos e não desejados. Porém, é tipicamente muito difícil reprogramar um ser vivo de modo a produzir o comportamento que se deseja. O desafio é se aprender a desenhar propriedades emergentes desejadas. Hoje, esse é o desafio científico chave da biologia de síntese.

A dificuldade da engenharia de emergência é bem conhecida, e atesta o fato que as propriedades emergentes não podem ser preditas. Há um pequeno argumento para sugerir como a engenharia de emergência é difícil; embora ele não esteja à altura do problema, ele torna a dificuldade visível. Supomos que a equipe do JCVI pode sintetizar células cujos genomas contêm um milhão de pares de bases. Levando-se em conta a existência de 4 nucleotídeos possíveis, tem-se $4^{1.000 .000}$, ou cerca de $10^{600.000}$, genomas possíveis com este tamanho. Isto é um número muito, muito, muito grande. $\mathrm{O}$ universo inteiro contém, estima-se, cerca de $10^{80}$ átomos de hidrogênio (o menor átomo). Para escrever esse número com seus oitenta zeros seriam necessárias duas linhas de texto. Em comparação, o número de diferentes genomas individuais que a equipe da JCVI poderia sintetizar tem seiscentos mil zeros, e completariam cerca de duzentos páginas. As sequências de A, C, G é $T$ de qualquer um desses genomas necessitariam de cerca de 350 páginas para escrevê-lo. A equipe do JCVI mostrou, de fato, que se pode sintetizar qualquer genoma específico desejado. Mas há duas coisas que, no entanto, ainda não se pode fazer. Primeiro, não se pode fazer todos os genomas possíveis. Mesmo se fosse possível reduzir cada genoma ao tamanho de um átomo de hidrogênio (o que não se sabe fazer), o universo inteiro conhecido seria pequeno demais para conter mais do que uma pequeníssima parte dos genomas. Segundo, não se teria a menor ideia de qual sequência específica produziria as características específicas desejadas na célula sintética. Ninguém sabe até agora quais genomas específicos produzem fontes de energia acessíveis e sustentáveis. Não é impossível apreender as soluçôes para esses problemas, mas se tem que 
levar em conta a complexidade das redes causais e as propriedades emergentes resultantes. Um desafio chave para a biologia de síntese, hoje, é conhecer as maneiras eficientes de engenhar as propriedades emergentes desejadas em uma célula sintética.

Jean Weissenbach, o diretor do instituto de pesquisa Genoscope em Evry, França, disse que aqueles que pretendem efetivamente criar vida a partir de matéria inerte, apenas fazem ficção científica. Você compartilha dessa opinião? Ou, ao contrário, será que esse objetivo lhe parece alcançável num futuro não tão distante? Quais são, a seu ver, as condições mínimas necessárias para alcançar esse objetivo - isto é, criar um sistema capaz de metabolizar e reproduzir - num sistema simples e artificial?

Estou convencido que é possível criar novas formas de vida nos laboratórios. Essas formas de vida serão provavelmente muito mais simples que qualquer organismo vivo existente, mas isso não é um problema. Não será uma surpresa para mim se isso acontecer durante nossa vida, ou mesmo na próxima década. Contudo, é difícil predizer o progresso da ciência e, por enquanto, somente um punhado de grupos de pesquisa no mundo tem recursos para trabalhar sobre protocélulas. Assim, ficaria surpreso se o objetivo de criar vida em laboratório não se realizasse daqui há algumas gerações.

Os pesquisadores no campo de protocélulas mais ou menos compartilham um consenso quanto à definição das condiçōes necessárias para uma vida química mínima. Chamo de modelo Program-Metabolism-Container (PMC). É um modelo químico funcional que não se preocupa com os detalhes tais como a natureza dos materiais químicos envolvidos, mas, ao contrário, se concentra em certas funções químicas, tais como a agregação, o metabolismo ou o isolamento espacial. Estas funções químicas podem ocorrer de diversas maneiras, e qualquer realização química correta da estrutura funcional PMC seria um exemplo de vida química mínima.

O modelo PMC considera que uma vida química mínima se estabelece em todo sistema químico desde que três funcionalidades químicas críticas estejam integradas, de tal maneira que cada uma sustente as outras. A primeira funcionalidade química ( $P$, para "programa") coloca as propriedades químicas do sistema sob o controle de uma informação hereditária, armazenada no sistema e que pode ser modificada no processo de reprodução. A segunda funcionalidade química (M, para "metabolismo") consiste em extrair energia livre do meio ambiente e digerir recursos disponíveis no meio ambiente para sustentar e corrigir o sistema, o fazer crescer e finalmente reproduzir-se. A terceira funcionalidade $(\mathrm{C}$, para "conteúdo") assegura que o sistema mantenha a sua identidade ao longo do tempo através da localização de todos os seus componentes, da concentração dos princípios reagentes e da proteção das operações químicas de parasitas moleculares e venenos.

No modelo PMC, os termos "programa", "metabolismo" e "conteúdo" devem ser entendidos por suas funcionalidades, com um mínimo de constrangimento sobre as suas realizações químicas. As funcionalidades $\mathrm{P}, \mathrm{M}$ e C não são somente contíguas no espaço; elas são quimicamente integradas e se sustentam mutuamente, de modo que o processo contínuo de cada componente depende do processo contínuo das duas outras componentes. Deste modo, a PMC integrada apresenta um tipo de cooperação química. O programa envolvido no sistema pode sustentar a tríade funcional quando sequências ou estruturas de biopolímeros têm propriedades catalíticas ou são usadas como matéria estrutural de um invólucro. De modo semelhante, um metabolismo pode abastecer a produção de pedaços constitutivos de paredes e de programas. As paredes celulares podem atuar como catalisadores de várias maneiras; por exemplo, as condiçōes termodinâmicas em um agregado de lipídeos ou na interface com um agregado de moléculas d'água, que diferem das condições termodinâmicas na água simples, podem ser catalíticas. Esses exemplos mostram como cada componente de um sistema PMC ajuda na operação das outras, e consequentemente, ajuda a assegurar o processo contínuo da tríade PMC inteira.

A biologia de síntese não somente trata da possível criação de vida a partir de matéria inerte, mas também se preocupa, de modo mais geral, a modificar organismos biológicos simples para que fabriquem produtos necessários para a economia humana. Artemisinina (uma substância promissora na luta contra a malária), o hormônio de crescimento, a hidrocortisona, e também os hidrocarbonetos que podem substituir os combustíveis fósseis, figuram entre os objetivos apontados pelas cerca de 500 companhias que já começaram a investir nesse campo. Será que estamos às vésperas de uma nova revolução industrial? Os países investem suficientemente na pesquisa no campo da biologia de síntese?

Estamos no início de uma revolução industrial envolvendo a biologia sintética. Haverá muitas oportunidades excelentes para empresários e investidores. Isso vai levar a muita publicidade, mas muito dinheiro vai ser ganho e perdido. Como já disse anteriormente, uma das oportunidades chave de negócio consiste em inventar e aperfeiçoar novas maneiras de engenhar os mecanismos bioquímicos complexos que levam às propriedades emergentes desejadas. Contudo, está além da minha competência especular se as oportunidades industriais na biologia sintética serão, ou não, muito melhores do que em ramos competitivos.

A biologia sintética não é somente cheia de promessas, mas também - como a maioria dos avanços científicos - um objeto de receio. Michele Garfinkel, que trabalhou no Centro de Genômica Avançada em Rockville, Maryland, EUA, disse que daqui a dez anos, sintetizar vários vírus patogênicos será mais fácil do que isolá-los em meio natural, de um paciente, ou que roubá-los de um laboratório de alta seguridade. Como podemos proteger a biologia de síntese contra aqueles que queiram "brincar de ser Deus"? 
Penso que as preocupações sobre o uso mal intencionado da biologia sintética são exageradas. Tem vias mais simples, menos caras e bem conhecidas para causar prejuízos e grandes alarmes do que a biologia de síntese do tipo faça você mesmo. Mas alguns receios sobre brincar de ser Deus podem ser mais graves. Esses receios são frequentemente denegados em bloco muito rapidamente. Por exemplo, Drew Endy disse "as questões de brincar ou não de ser Deus são tão superficiais e simplistas que não vale a pena levar em consideração na discussão". Em contraste, acho que devemos distinguir as formas diferentes desses receios, pois algumas são, de fato, muito antigas e dizem respeito a cada um de nós.

Ninguém pensa que biólogos de síntese podem criar a vida a partir de nada; uma criação ex nihilo é impossível. Do mesmo modo, ninguém contesta que criar as condições, nos laboratórios, necessárias para sintetizar a vida exige muito cuidado e muita inteligência. Os cientistas envolvidos são seres vivos, portanto, pode-se dizer que formas de vida sintética não vão emergir num mundo completamente desprovido de outras formas de vida. Mas os pesquisadores de fato estão procurando criar formas de vida sintética usando somente materiais inertes, o tipo de materiaes que se pode comprar num fornecedor de produtos químicos. Essa meta, por enquanto, é um sonho científico, mas ela já é um forte incentivo para biólogos de síntese do tipo bottom-up. Na minha opinião, veremos num futuro não tão distante a criação de formas de vida sintética a partir de materiais exclusivamente inertes.

O que dizer sobre a preocupação de que somente Deus pode criar novas formas de vida? Uma perspectiva religiosa sobre o problema de criar vida sintética pode conter muita sapiência, mas qualquer sabedoria baseada somente em dogmas religiosos será ignorada pelos não crentes. Então os receios religiosos sobre o fato de brincar de ser Deus tendem a desencorajar qualquer discussão fecunda.

Porém, uma terceira forma de receio de brincar de ser Deus ainda existe. Nossos poderes de criar novas formas de vida estão em progresso e em desenvolvimento, de modo que é cada vez mais urgente exercer essas capacidades de uma maneira prudente e responsável. A capacidade para uma reprodução exponencialmente crescente e para uma evolução sem limites é o que viabiliza a existência de formas vivas tão poderosas e tão potencialmente úteis, mas que são também formas de vida particularmente difíceis de predizer e de controlar. Isso gera uma forma pragmática e totalmente secular sobre o receio de brincar de ser Deus. O receio é saber se humanos terão o entendimento e a sapiência que queremos ver em qualquer pessoa que está criando novas formas de vida. Queríamos outorgar essa responsabilidade a pessoas com um discernimento parecido ao de Deus sobre as consequências de vários atos, uma sabedoria parecida a de Deus sobre a maneira de promover as melhores vantagens para eles, e um poder parecido ao de Deus de enfrentar qualquer problema imprevisto. O que pode alimentar esse receio é a empáfia da gente que dispõe de tecnologias emergentes poderosas e imprevisíveis. Somos espertos, benevolentes, e responsáveis o bastante para lidar com a biologia sintética e com a ciência das protocélulas? Essa forma pragmática e secular de apreensão a propósito de se brincar de ser Deus merece a atenção de todos, mesmo dos ateus.
Quando decidimos o que fazer com sistemas complexos que manifestam propriedades emergentes fracas, geralmente estamos decidindo às cegas. Decidir às cegas não é um caso considerado pela teoria de decisão tradicional. Decidimos às cegas quando devemos tomar uma decisão embora estejamos fundamentalmente incertos sobre as consequências das nossas decisões; a nossa decisão está cheia de incertezas desconhecidas. Às vezes não sabemos os resultados das várias escolhas possíveis, de tal modo que não podemos identificar os ramos da árvore de decisões. Somos, às vezes, ignorantes sobre as verdadeiras utilidades gerais associadas a cada ramo, de modo que não os podemos avaliar. As propriedades emergentes fracas associadas à vida são, naturalmente, a razão dessas incertezas. As propriedades emergentes fracas, por definição, são tão complexas que predizê-las é impossível, e ficamos na obscuridade sobre as suas consequências ao menos que possamos seguir passo a passo a rede de causas. É por isso que, nessa situação, a teoria da decisão tradicional oferece tão pouca ajuda para as nossas decisões.

\section{NOTA BIBLIOGRÁFICA}

1. Estocasticidade: propriedade de todo sistema cujo comportamento se complica com a ação de fatores fortuitos, ao acaso. 